\title{
Morfometria de testículos escrotais, abdominais e inguinais de eqüinos criptórquios unilaterais
}

[Morphometry of scrotal, abdominal and inguinal testes of unilateral cryptorchid horses]

\author{
J.W. Cattelan ${ }^{1}$, I.C. Boleli ${ }^{2}$, E.B. Malheiros ${ }^{2}$, P.A. Barnabe ${ }^{3}$ \\ ${ }^{1}$ Faculdade de Ciências Agrárias e Veterinárias - UNESP \\ Via de Acesso Prof. Paulo Donato Castellane, $\mathrm{s} / \mathrm{n}^{\circ}$ \\ 14884-900 - Jaboticabal, SP \\ ${ }^{2}$ FCAV - UNESP - Jaboticabal, SP \\ ${ }^{3}$ Doutoranda - FCAV- UNESP - Jaboticabal, SP
}

\begin{abstract}
RESUMO
Foi realizado um estudo morfométrico de testículos escrotais e retidos de 10 eqüinos criptórquios unilaterais, sendo cinco abdominais e cinco inguinais. As características avaliadas foram espessura da albugínea testicular, área dos túbulos seminíferos e número de células de Leydig. A espessura da albugínea testicular mostrou-se reduzida $(\mathrm{P} \leq 0,05)$ nas gônadas criptórquias abdominais quando comparadas às escrotais contralaterais. Também foram observadas diferenças $(\mathrm{P} \leq 0,01)$ nas áreas dos túbulos seminíferos dos testículos abdominais e inguinais, que se apresentaram diminuídas quando comparadas às dos escrotais contralaterais. A diminuição foi de, aproximadamente, $45 \%$ nos testículos abdominais e de $31 \%$ nos inguinais. Não foram verificadas diferenças $(\mathrm{P}>0,05)$ na contagem de células de Leydig das gônadas criptórquias comparadas às escrotais contralaterais. Nos eqüinos, o criptorquismo afetou com maior intensidade a área dos túbulos seminíferos dos testículos abdominais e inguinais e a espessura da albugínea daqueles retidos no abdome.
\end{abstract}

Palavras-chave: cavalo, criptorquismo, morfometria, testículo

\begin{abstract}
Morphometrical study was performed in scrotal and retained testes of 10 unilateral cryptorchid horses, five abdominal and five inguinal. Thickness of the testicular albuginea, area of seminiferous tubules and number of Leydig cells were evaluated. Abdominal retained testes showed a reduction in the thickness of testicular albuginea in comparison to the contralateral scrotal testes $(P \leq 0.05)$. Significant reduction $(P \leq 0.01)$ in the area of the seminiferous tubules was observed for the retained testes. These reductions were approximately $45 \%$ in the abdominal testes and $31 \%$ in the inguinal ones. No differences $(P>0.05)$ were observed in the Leydig cell count of the retained testes in comparison to the contralateral scrotal testes, justifying that testosterone production in the cryptorchid horses was similar to the normal stallion. The equine cryptorchidism affected with major intensity the area of seminiferous tubules of abdominal and inguinal testes and the thickness of testicular albuginea of the abdominal testes.
\end{abstract}

Keywords: horse, cryptorchism, morphometry, testis

Recebido para publicação em 26 de abril de 2004

E-mail: cattelan@fcav.unesp.br 


\section{INTRODUÇÃO}

Testículos criptórquios de eqüinos são menores que os escrotais (Bishop et al., 1964; Arighi et al., 1987; Al-Bagdadi et al., 1991; Aupperle et al., 1999) e, histologicamente, são semelhantes aos testículos com hipoplasia total ou degeneração avançada do epitélio seminífero (Nascimento e Santos, 2003). Mostram vacuolização dos túbulos seminíferos (Arighi et al., 1987; Al-Bagdadi et al., 1991), aumento do conjuntivo intersticial (Al-Bagdadi et al., 1991; Nascimento e Santos, 2003) e, às vezes, discreta hiperplasia das células intersticiais de Leydig (Nascimento e Santos, 2003), mais evidente nas gônadas retidas no abdome (Arighi et al., 1987).

As gônadas apresentam redução no diâmetro dos túbulos seminíferos (Coryn et al., 1981; Arighi et al., 1987) e no número de camadas de células espermatogênicas (Arighi et al., 1987), sendo afuncionais sob o ponto de vista espermatogênico (Coryn et al., 1981; Arighi et al., 1987; Aupperle et al., 1999; Cattelan, 2002; Nascimento e Santos, 2003).

Apesar da interrupção da espermatogênese observada nos testículos criptórquios de eqüinos (Coryn et al., 1981; Arighi et al., 1987; Aupperle et al., 1999; Cattelan, 2002), suas células de
Leydig mantêm aspecto histologicamente normal (Bishop et al., 1964; Coryn et al., 1981; Arighi et al., 1987; Aupperle et al., 1999) e a concentração sérica de testosterona é similar à de garanhões normais (Coryn et al., 1981; Arighi et al., 1986; Cattelan, 2002), inclusive nos criptórquios unilaterais, cujo testículo escrotal foi removido cirurgicamente (Coryn et al., 1981; Arighi et al., 1986).

A carência de informações a respeito das alterações morfológicas a que os testículos escrotais e retidos de eqüinos criptórquios estão submetidos enseja investigações sobre o assunto. Assim, os objetivos deste estudo incluíram a mensuração da espessura da albugínea testicular, da área dos túbulos seminíferos e do número de células de Leydig nas gônadas criptórquias e nas escrotais contralaterais.

\section{MATERIAL E MÉTODOS}

Foram utilizados 10 eqüinos portadores de criptorquismo unilateral, cinco abdominais e cinco inguinais, de diferentes raças e idades (Tab. 1), que não haviam sofrido orquiectomia da gônada escrotal. Somente foram considerados criptórquios inguinais animais cujo testículo retido encontrava-se no canal inguinal.

Tabela 1. Animais usados no estudo morfométrico conforme classificação do criptorquismo, raça e idade

\begin{tabular}{lcc}
\hline Classificação do criptorquismo & Raça & Idade \\
\hline Abdominal unilateral direito & Puro Sangue Inglês & 5 anos \\
Abdominal unilateral esquerdo & Mangalarga & 2 anos e 6 meses \\
Abdominal unilateral esquerdo & Quarto de Milha & 4 anos \\
Abdominal unilateral esquerdo & Quarto de Milha & 4 anos e 2 meses \\
Abdominal unilateral esquerdo & Sem raça definida & 3 anos \\
Inguinal unilateral direito & Mangalarga & 5 anos \\
Inguinal unilateral direito & Puro Sangue Andaluz & 4 anos \\
Inguinal unilateral direito & Brasileiro de Hipismo & 2 anos e 11 meses \\
Inguinal unilateral direito & Sem raça definida & 5 anos \\
Inguinal unilateral esquerdo & Sem raça definida & 5 anos \\
\hline
\end{tabular}

Os testículos abdominais foram removidos por laparotomia paramediana paraprepucial, conforme Wright (1960), os inguinais extirpados por criptorquidectomia inguinal e os escrotais por orquiectomia convencional segundo Bishop et al. (1964).
Foram colhidos fragmentos de, aproximadamente, $2 \times 1 \times 1 \mathrm{~cm}$ na face abepididimal dos testículos extirpados, imediatamente após a criptorquidectomia e orquiectomia. As amostras foram imersas em solução de Bouin por 24 horas para fixação e, em 
seguida, mantidas em álcool $70 \%$ até seu processamento histológico de rotina para inclusão em parafina. Cortes histológicos de $6 \mu \mathrm{m}$ de espessura foram corados pela hematoxilinaeosina ou tricrômico de Masson, segundo Behmer et al. (1976).

O estudo morfométrico foi realizado em microscópio óptico adaptado a um sistema de análise de imagens ${ }^{1}$. Foram avaliados três cortes de cada testículo para mensuração da espessura da albugínea testicular $(\mu \mathrm{m})$, da área média total de túbulos seminíferos (dada como percentual em relação aos campos microscópicos analisados) e do número de células de Leydig $\left(\mathrm{n}^{\circ} / 15.134 \mu \mathrm{m}^{2}\right)$. Em cada corte foram obtidas cinco medidas de espessura da albugínea testicular, oito campos de leitura das áreas dos túbulos seminíferos e 15 campos de contagem de células de Leydig, totalizando, respectivamente, 15, 24 e 45 análises de cada um dos parâmetros pesquisados por testículo examinado. As mensurações foram realizadas em campos selecionados aleatoriamente.

As comparações entre as gônadas escrotais com as criptórquias abdominais ou inguinais contralaterais para as médias das variáveis estudadas foram feitas pelo teste $t$.

\section{RESULTADOS E DISCUSSÃO}

As médias obtidas para espessura da albugínea, área dos túbulos seminíferos e número de células de Leydig, juntamente com o resumo da análise estatística, encontram-se na Tab. 2.

Tabela 2. Média, desvio-padrão (DP) e estatística t, com respectiva probabilidade (P), da espessura da albugínea testicular, área dos túbulos seminíferos e número de células de Leydig de testículos escrotais, abdominais e inguinais de cavalos criptórquios unilaterais

\begin{tabular}{|c|c|c|c|c|c|}
\hline Variável & Testículo & Média \pm DP & Comparação & $\mathrm{t}$ & $\mathrm{P}$ \\
\hline \multirow{5}{*}{$\begin{array}{l}\text { Espessura da } \\
\text { albugínea }(\mu \mathrm{m})\end{array}$} & $\begin{array}{l}\text { TE } \\
\text { TC }\end{array}$ & $\begin{array}{l}1759,6 \pm 399,6 \\
1438,1 \pm 472,6\end{array}$ & $\mathrm{TE} \times \mathrm{TC}$ & 2,67 & $0,025^{*}$ \\
\hline & TEA & $1983,8 \pm 210,0$ & \multirow{2}{*}{ TEA $\times$ TCA } & \multirow{2}{*}{3,11} & \multirow{2}{*}{$0,036^{*}$} \\
\hline & TCA & $1475,0 \pm 217,5$ & & & \\
\hline & TEI & $1535,3 \pm 435,4$ & \multirow{2}{*}{$\mathrm{TEI} \times \mathrm{TCI}$} & \multirow{2}{*}{0,93} & \multirow{2}{*}{$0,40 \mathrm{NS}$} \\
\hline & $\mathrm{TCl}$ & $1401,1 \pm 672,2$ & & & \\
\hline \multirow{4}{*}{$\begin{array}{l}\text { Área dos túbulos } \\
\text { seminíferos (\%) }\end{array}$} & $\begin{array}{l}\text { TE } \\
\text { TC }\end{array}$ & $\begin{array}{c}12,2 \pm 3,9 \\
7,4 \pm 3,4\end{array}$ & $\mathrm{TE} \times \mathrm{TC}$ & 13,82 & $0,0001 * *$ \\
\hline & TEA & $13,0 \pm 4,6$ & \multirow{2}{*}{ TEA $\times$ TCA } & \multirow{2}{*}{11,87} & \multirow{2}{*}{$0,0001 * *$} \\
\hline & TCA & $7,0 \pm 3,1$ & & & \\
\hline & $\begin{array}{l}\text { TEI } \\
\text { TCI }\end{array}$ & $\begin{array}{c}11,4 \pm 3,1 \\
7,8 \pm 3,6\end{array}$ & $\mathrm{TEI} \times \mathrm{TCI}$ & 7,94 & $0,0001 * *$ \\
\hline \multirow{4}{*}{$\begin{array}{l}\text { Células de Leydig } \\
\left(\mathrm{n} / 15,134 \mu \mathrm{m}^{2}\right)\end{array}$} & $\begin{array}{l}\mathrm{TE} \\
\mathrm{TC}\end{array}$ & $\begin{array}{l}10,5 \pm 3,0 \\
10,7 \pm 3,9\end{array}$ & $\mathrm{TE} \times \mathrm{TC}$ & $-0,16$ & $0,88 \mathrm{NS}$ \\
\hline & $\begin{array}{l}\text { TEA } \\
\text { TCA }\end{array}$ & $\begin{array}{c}11,0 \pm 4,2 \\
8,4 \pm 2,6\end{array}$ & TEA $\times$ TCA & 1,58 & $0,19 \mathrm{NS}$ \\
\hline & TEI & $11,0 \pm 1,7$ & \multirow{2}{*}{$\mathrm{TEI} \times \mathrm{TCI}$} & \multirow{2}{*}{$-1,97$} & \multirow{2}{*}{$0,12 \mathrm{NS}$} \\
\hline & TCI & $13,0 \pm 3,8$ & & & \\
\hline
\end{tabular}

$\mathrm{NS}=$ não significativo $(\mathrm{P}>0,05) ;{ }^{*}=$ significativo $(\mathrm{P} \leq 0,05) ;{ }^{*}=$ significativo $(\mathrm{P} \leq 0,01) ; \mathrm{TC}=$ testículo criptórquio; TCA $=$ testículo criptórquio abdominal; TCI $=$ testículo criptórquio inguinal; $\mathrm{TE}=$ testículo escrotal; TEA = testículo escrotal do criptórquio abdominal; TEI = testículo escrotal do criptórquio inguinal.

\footnotetext{
${ }^{1}$ Videoplan - Kontron Elektronik, Germany
} 
Quanto à espessura da albugínea testicular, verificaram-se diferenças $(\mathrm{P} \leq 0,05)$ entre as gônadas escrotais e as criptórquias (TE $\times \mathrm{TC}) \mathrm{e}$ entre as escrotais $\mathrm{e}$ as abdominais dos criptórquios abdominais (TEA $\times$ TCA). Como no criptorquismo há diminuição no tamanho do testículo (Bishop et al., 1964; Arighi et al., 1987; Al-Bagdadi et al., 1991; Aupperle et al., 1999), é possível que a redução da espessura da albugínea testicular ocorra simultaneamente à da gônada e contribua para a maior predisposição do testículo retido aos efeitos deletérios da temperatura mais elevada da cavidade abdominal. Este fato pode justificar a maior severidade das alterações degenerativas encontradas nas células espermatogênicas dos túbulos seminíferos de testículos criptórquios por Al-Bagdadi et al. (1991) e Aupperle et al. (1999), as quais foram mais evidentes nos testículos abdominais que nos inguinais.

Foram observadas diferenças $(\mathrm{P} \leq 0,01)$ entre gônadas quanto às áreas dos túbulos seminíferos que se mostraram reduzidas nas gônadas criptórquias em todas as comparações feitas. A redução foi de aproximadamente $45 \%$ nos testículos abdominais e de $31 \%$ nos inguinais. Este resultado confirma os já descritos por Coryn et al. (1981) e Arighi et al. (1987), que também verificaram redução no tamanho dos túbulos seminíferos de testículos criptórquios e no número de camadas de células espermatogênicas (Arighi et al., 1987), o que possivelmente explica a redução da área dos túbulos seminíferos observada. Todavia, diferente dos resultados desta pesquisa, Al-Bagdadi et al. (1991) observaram que os túbulos seminíferos dos testículos abdominais eram maiores do que os dos inguinais.
Não houve diferença entre gônadas quanto ao número de células de Leydig $(\mathrm{P}>0,05)$. Este resultado difere dos apresentados por Arighi et al. (1987) e Nascimento e Santos (2003), que relataram aumento do número dessas células em testículos criptórquios. No exame histológico das gônadas criptórquias verificouse diminuição acentuada do tamanho dos túbulos seminíferos, que se apresentaram aglomerados e circundados por células de Leydig, as quais apareceram concentradas ao redor dos túbulos, causando no observador a impressão de que o número delas estava aumentado (Fig. 1). Contudo, os resultados indicaram que essa observação não foi condizente, pois não houve diferença $(\mathrm{P}>0,05)$ no número de células de Leydig $\left(\mathrm{n}^{\circ} / 15.134 \mu \mathrm{m}^{2}\right)$, quando se fez a comparação entre os grupos. Esse fato, associado ao aspecto histológico normal das células de Leydig (Bishop et al., 1964; Coryn et al., 1981; Arighi et al., 1987; Aupperle et al., 1999), pode justificar a produção de testosterona nos cavalos criptórquios, similar à de garanhões normais, conforme Coryn et al. (1981), Arighi et al. (1986) e Cattelan (2002).

Portanto, nos eqüinos, o criptorquismo afeta com maior intensidade a área dos túbulos seminíferos dos testículos abdominais e inguinais e a espessura da albugínea testicular das gônadas retidas no abdome.

\section{AGRADECIMENTO}

Ao técnico de laboratório Orandi Mateus, pela confecção das lâminas usadas neste estudo. 

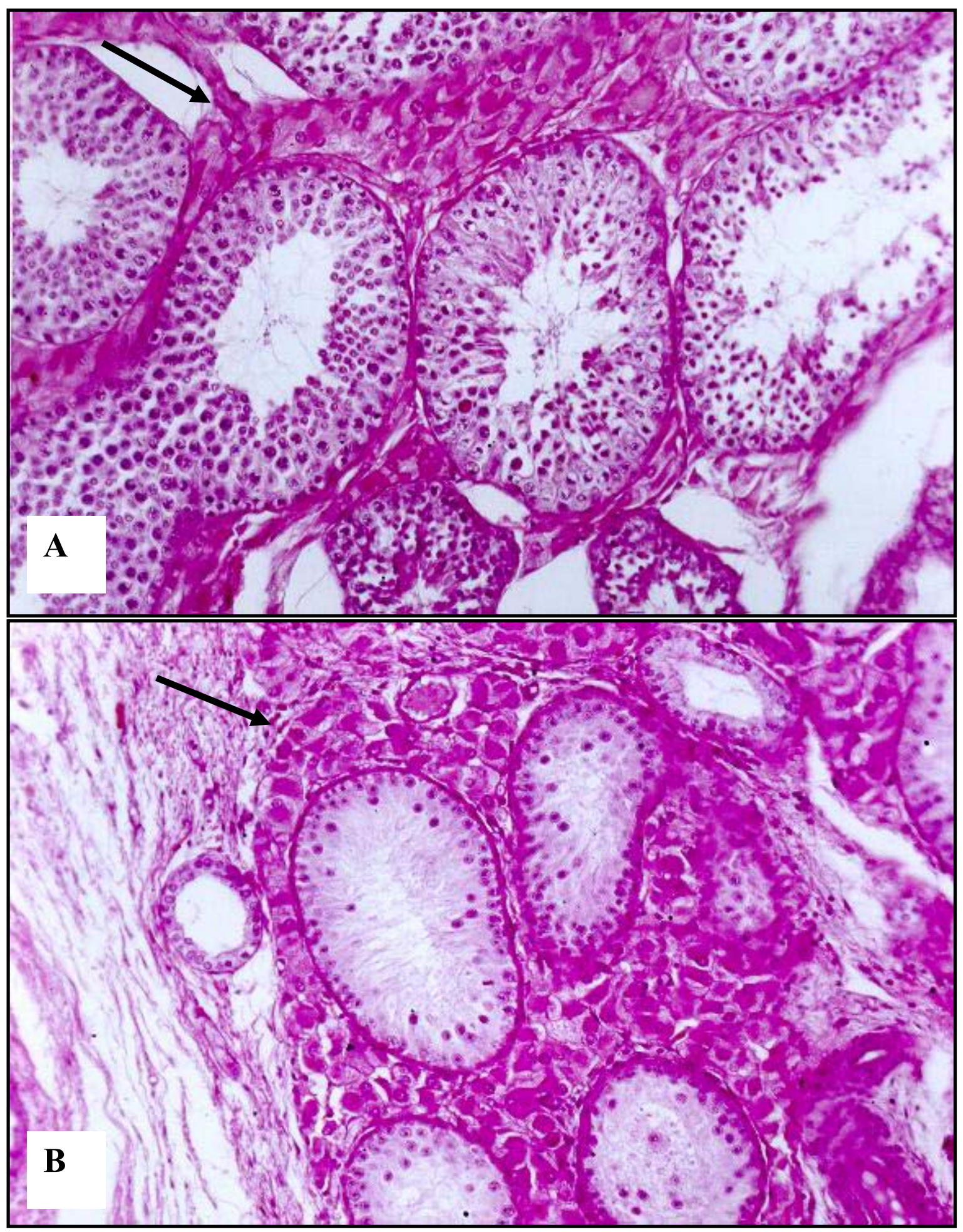

Figura 1. Testículo escrotal (A) e criptórquio inguinal (B) de cavalo Puro Sangue Andaluz de quatro anos de idade. Notar células de Leydig (setas) ao redor dos túbulos seminíferos. Hematoxilina-eosina. Objetiva $20 \mathrm{X}$. 


\section{REFERÊNCIAS BIBLIOGRÁFICAS}

AL-BAGDADI, F.; HOYT, P.; KARNS, P. et al. The morphology of abdominal and inguinal cryptorchid testes in stallions: a light and electron microscopic study. Int. J. Fertil., v.36, p.57-64, 1991.

ARIGHI, M.; BOSU, W.T.K.; RAESIDE, J.I. Hormonal diagnosis of equine cryptorchidism and histology of the retained testes. In: ANNUAL CONVENTION OF THE AMERICAN ASSOCIATION OF EQUINE PRACTITIONERS, 31., 1986, Toronto. Proceedings... Toronto: American Association of Equine Practitioners, 1986. p.591-602.

ARIGHI, M.; SINGH, A.; BOSU, W.T.K. et al. Histology of the normal and retained equine testis. Acta Anat., v.129, p.127-130, 1987.

AUPPERLE, H.; GERLACH, K.; BARTMANN, C.P. et al. Histopathological findings in the cryptorchid testes of stallions. Pferdeheilkunde, v.15, p.515-522, 1999.

BEHMER, O.A.; TOLOSA, E.M.C.; FREITAS NETO, A.G. (Eds.). Manual de técnicas para histologia normal e patológica. São Paulo: Edart, 1976. 256p.

BISHOP, M.W.H.; DAVID, J.S.E.; MESSERVY, A. Some observations on cryptorchidism in the horse. Vet. Rec., v.76, p.1041-1048, 1964.

CATTELAN, J.W. Aspectos de casuística, morfométricos, morfológicos e de testosterona sérica no criptorquismo em cavalos. 2002. 64f. Tese (Livre-Docência em Clínica Cirúrgica de Grandes Animais) - Faculdade de Ciências Agrárias e Veterinárias, Universidade Estadual Paulista, Jaboticabal, SP.

CORYN, M.; De MOOR, A.; BOUTERS, R. et al. Clinical, morphological and endocrinological aspects of cryptorchidism in the horse. Theriogenology, v.16, p.489-496. 1981.

NASCIMENTO, E.F.; SANTOS, R.L. (Eds). Patologia da reprodução dos animais domésticos. 2.ed. Rio de Janeiro: Guanabara Koogan, 2003. p.93-104.

WRIGHT, J.G. Laparo-orchidectomy in the horse with abdominal cryptorchidism. Vet. Rec., v.72, p.57-60, 1960. 